\title{
Implementing tobacco control policies for minority youth with second-hand smoke exposure and respiratory disease
}

\author{
Arlene M Butz
}

In Thorax, Neophytou and colleagues present evidence of a dose-response between second-hand smoke (SHS) exposure and asthma exacerbations and poor asthma control in minority children enrolled in either the Gene-environments and Admixture in Latino Americans (GALA II) or the Study of African-Americans, Asthma, Genes and Environments (SAGE II) studies. ${ }^{1}$ SHS exposure, defined as plasma cotinine level $>0.05 \mathrm{ng} / \mathrm{mL}$ or above the limit of quantitation/concentration for reporting results with high confidence, was significantly associated with increased odds of poorly controlled asthma in African-American children. This association was not as strong in Latino youth. Further, the odds for experiencing an asthma exacerbation in the prior 12 months based on plasma cotinine levels $>0.05 \mathrm{ng} / \mathrm{mL}$ was $1.40 \quad(95 \%$ CI 1.03 to 1.89 ) but was not significant based on self-reported SHS exposure. ${ }^{1}$ Even at low exposure concentrations, a dose-response between plasma cotinine and asthma exacerbations was noted. Why is this significant? The study provides convincing data, in terms of asthma outcomes, that there are no safe levels of SHS exposure, irrespective of the child's racial/ethnic group.

In 2017, WHO developed the Framework Convention on Tobacco Control (WHO FCTC) based on the six 'MPOWER' measures to provide global 'best practice' guidelines to reduce tobacco consumption and second-hand smoke exposure via national tobacco control programmes. ${ }^{2}$ Implementation of the six MPOWER strategies (monitor tobacco use and prevention policies, protect people from tobacco smoke, assistance with quitting tobacco use, warn people about dangers of tobacco, enforce bans on tobacco advertising, promotion and sponsorship and increase taxes on tobacco) must be strongly supported by the paediatric lung health community especially in light of the evidence that even low exposure is associated with poor asthma control. Yet, almost half of children globally breathe

Correspondence to Dr Arlene M Butz, Department of Pediatrics, Johns Hopkins University School of Medicine, Baltimore, MD 21205, USA; abutz@jhmi.edu
SHS from tobacco in public places on a regular basis. ${ }^{2}$ Therefore, the major unanswered question from the Neophytou study is where do we go from here to reduce SHS exposure in minority children with chronic and acute respiratory disease?

It may be time to implement cotinine screening for all children treated for any chronic respiratory disease in primary and acute care settings. Determining child SHS exposure based on parental reports results in significant misclassification. Neophytou and colleagues indicate that misclassification of non-smoking exposure was detected in $41 \%$ of children. ${ }^{1}$ This misclassification was due to parental report of no current smokers in the household, while the child had a plasma cotinine concentration above the $0.05 \mathrm{ng} / \mathrm{mL}$ cut-off indicating positive SHS exposure. Prior misclassification rates of non-SHS exposure ranged from 19\% to $57 \%,{ }^{34}$ suggesting that parental report of SHS exposure is unacceptable when objective measures of SHS exposure are available, valid and mostly non-invasive. Nevertheless, few healthcare professionals use nicotine biomarkers as an objective measure for SHS exposure. ${ }^{5}$ Barriers to screening for SHS exposure using biomarkers among children with respiratory disease in acute and primary care settings include feasibility, cost and need for medical staff to follow up patients with positive cotinine results. ${ }^{6}$ Although select commercial laboratories provide salivary cotinine measurement, few general or paediatric practitioners order cotinine tests primarily due to one of these barriers.

Simple cotinine screening test strips are available to estimate urine cotinine concentrations in clinical settings; however, the test strips are primarily used in research studies. ${ }^{7}$ The urine cotinine test strips, using an immunochromatographic assay, provide real-time results within 5-10 $\mathrm{min}$ and have cut-off points consistent with prior urine cotinine testing ranges. ${ }^{8}$ For example, a 6-minute disposable point-of-care urine test measuring nicotine and metabolites (SmokeScreen) was used in an intervention to provide feedback to inner-city pregnant women to encourage smoking cessation. ${ }^{9}$ Similarly, NicCheck I urine cotinine test strips were evaluated in pregnant women attending private Japanese urban prenatal clinics as a way to monitor maternal SHS exposure. ${ }^{10}$ Although these point-of-care urine cotinine tests are less stressful than using hair or saliva samples, NIcCheck I may not be as sensitive in light tobacco smokers as compared with moderate or heavy smokers. ${ }^{11}$ Recently, a modified SmokeScreen test strip was developed to detect lower levels of cotinine found in saliva and was evaluated in healthy volunteers of whom half were smokers. ${ }^{12}$ The salivary cotinine test strip was easy to interpret based on a 4-point colour chart, and also the test had high sensitivity and specificity (90\% and 98\%, respectively). ${ }^{12}$ Use of salivary cotinine testing to promote smoking cessation was further supported with adult dental patients who smoke, indicating the feasibility of use in primary care settings. ${ }^{13}$

In paediatric clinical settings, serum cotinine testing was strongly accepted by parents when testing was an 'add-on' or discarded plasma was used during an existing blood test such as routine lead testing. ${ }^{14-16}$ The availability of immediate test results for SHS exposure may lead to a discussion between the healthcare provider and parent regarding how to protect the child from exposure to tobacco smoke, for example, implementing household smoking bans and seeking smoking cessation treatment, two MPOWER best practice measures. Further, the cotinine results may influence clinical decision-making for stepwise asthma treatment in children with positive SHS exposure. Despite these advances, cotinine screening test strips are more widely reported in epidemiological and research studies rather than in routine preventive patient care settings. ${ }^{12}$ New untried models of care incorporating cotinine testing into routine care for children with chronic respiratory disease are needed.

The understanding of patterns of SHS exposure for the child (parental smoking in bedroom, visitors who smoke around child, relatives or daycare workers who smoke near child) is as important as detecting SHS exposure. Characterising the precise sites and context of cigarette smoking in the child's environment can inform high-impact practices to reduce and eliminate SHS exposure in children. For instance, understanding shared ventilation systems in multiunit housing including subsidised housing ${ }^{17}$ may inform effective strategies to reduce SHS exposure in child residents of this type of housing.

Stronger advocacy by the paediatric lung health community to initiate biochemical 
monitoring of SHS exposure of all children with chronic respiratory disease is a first step. Future studies that map all SHS exposure of minority children with respiratory disease may result in effective SHS reduction strategies specific to racial/ ethnic paediatric groups that currently are not well understood. Increased monitoring of SHS exposure using biomarkers along with comprehensive smoke-free legislation, bans on tobacco advertising, promotion and sponsorship may result in policies to protect lung health in children. Children are the 'missing voice' in the global tobacco epidemic and deserve a tobacco-free environment. ${ }^{18}$ How we achieve this goal requires stronger advocacy for SHS exposure monitoring in high-risk paediatric populations to protect the health and well-being of minority children with respiratory disease.

Funding The author is funded by National Institute of Nursing Research, National Institutes of Health (NIH) grant number NR013486.

Competing interests None declared.

Patient consent Not required.

Provenance and peer review Commissioned; internally peer reviewed.

(C) Author(s) (or their employer(s)) 2018. No commercial re-use. See rights and permissions. Published by BMJ.

\section{Check for updates}

To cite Butz AM. Thorax 2018;73:1004-1005.

Accepted 16 July 2018

Published Online First 26 July 2018

\section{Linked}

http://dx.doi.org/10.1136/thoraxjnl-2017-211383

Thorax 2018:73:1004-1005.

doi:10.1136/thoraxjnl-2018-212071

\section{REFERENCES}

1 Neophytou AM, Oh SS, White MJ, et al. Secondhand smoke exposure and asthma outcomes among AfricanAmerican and Latino children with asthma. Thorax 2018;73:1041-8.

2 World Health Organization (WHO). WHO Report on the Global Tobacco Epidemic, 2017. Monitoring tobacco use and prevention policies. Geneva: World Health Organization, 2017.

3 Jeemon P, Agarwal S, Ramakrishnan L, et al. Validation of self-reported smoking status by measuring serum cotinine levels: an Indian perspective. Nat/ Med I India 2010;23:134-6.

4 Boyaci H, Etiler N, Duman C, et al. Environmental tobacco smoke exposure in school children: parent report and urine cotinine measures. Pediatr Int 2006:48:382-9.

5 U.S. Department of Health and Human Services. The Health Consequences of Smoking - 50 Years of Progress: A Report of the Surgeon General. Atlanta: U.S. Department of Health and Human Services, Centers for Disease Control and Prevention, National Center for Chronic Disease Prevention and Health Promotion, Office on Smoking and Health 2014.

6 Butz A, Bellin MH, Bollinger ME, et al. Salivary cotinine measurement for all children with persistent asthma: spit matters. Ann Allergy Asthma Immunol 2016;116:463-5.

7 Bernert JT, Harmon TL, Sosnoff CS, et al. Use of continine immunoassay test strips for preclassifying urine samples from smokers and nonsmokers prior to analysis by LC-MS-MS. J Anal Toxicol 2005;29:814-8.

8 Benowitz NL, Bernert JT, Caraballo RS, et al. Optimal serum cotinine levels for distinguishing cigarette smokers and nonsmokers within different racial/ethnic groups in the United States between 1999 and 2004. Am J Epidemiol 2009;169:236-48.

9 Cope GF, Nayyar P, Holder R. Feedback from a point-ofcare test for nicotine intake to reduce smoking during pregnancy. Ann Clin Biochem 2003;40:674-9.

10 Higashida Y, Ohashi K. Reduction of tobacco smoke exposure for pregnant passive smokers using feedback of urinary cotinine test results. J Obstet Gynaecol Res 2014:40:1015-22.

11 Bernaards CM, Twisk JW, van Mechelen W, et al Comparison between self-report and a dipstick method (NicCheck 1) to assess nicotine intake. Eur Addict Res 2004;10:163-7.

12 Cope GF, Wu HH, O'Donovan GV, O'Donovan MHJ, et al. A new point of care cotinine test for saliva to identify and monitor smoking habit. Eur Respir J 2012;40:496-7.

13 Barnfather KD, Cope GF, Chapple IL. Effect of incorporating a 10 minute point of care test for salivary nicotine metabolites into a general practice based smoking cessation programme: randomised controlled trial. BMJ 2005:331:999

14 Joseph A, Murphy S, Thomas J, et al. A pilot study of concurrent lead and cotinine screening for childhood tobacco smoke exposure: effect on parental smoking Am J Health Promot 2014;28:316-20.

15 Winickoff JP, Tanski SE, McMillen RC, et al. Acceptability of testing children for tobacco-smoke exposure: a national parent survey. Pediatrics 2011;127:628-34.

16 Dempsey DA, Meyers MJ, Oh SS, et al. Determination of tobacco smoke exposure by plasma cotinine levels in infants and children attending urban public hospital clinics. Arch Pediatr Adolesc Med 2012;166:851-6.

17 Gentzke AS, Hyland A, Kiviniemi M, et al. Attitudes and experiences with secondhand smoke and smoke-free policies among subsidised and market-rate multiunit housing residents living in six diverse communities in the USA. Tob Control 2018;27:194-202.

18 Toebes B, Gispen ME, Been JV, et al. A missing voice: the human rights of children to a tobacco-free environment. Tob Control 2018:27:3-5. 